\title{
Editorial Commentary: Some Parting Thoughts
}

$\mathrm{t}$ has been said that a person
is almost guaranteed to mak enemies in the academic world by performing any one of the following three tasks: serving as the chair or head of a department, conducting book reviews, and acting as the editor for a journal. Given that both of us have performed all of the above simultaneously during a large part of the $1980 \mathrm{~s}$, it might be argued that we are definite gluttons for punishment!

Despite the problems associated with producing a product that needed to withstand scrutiny both within and outside landscape architecture - and also appear in a timely manner twice $\stackrel{\circ}{\subseteq}$ each year - the majority of our work as F co-editors of Landscape Journal certainly was enjoyable and stimulating.

Undoubtedly the greatest satisfaction occurred each time a new issue was กิ sent out to subscribers. The sight of the ¿ cover and another selection of articles i made us realize time and time again that landscape architecture is definitely 穵 on its way to achieving disciplinary ธิ status. We certainly appreciate the sup$\overrightarrow{0}$ port that all of you have given the Eo Journal since the first issue came out in ¿ early 1982, and are happy that we have E been able to provide opportunities for the publication of so much excellent ? work.

Valedictories are an appropriate time to give credit to individuals who have played a major role in transforming dreams into reality. First, of course, is the membership of CELA and its
Board who were willing to use resources from the organization's treasury as seed money for a refereed journal that would serve as an outlet for research and scholarship in landscape architecture. When coupled with the financial assistance provided by the Graduate School of the University of Wisconsin to the University of Wisconsin Press, we were able to launch a new publication within the space of just over a year. Both the Graduate School and Press need to be acknowledged for providing support during those initial years when subscriber funds never seemed to match publication and promotion expenses.

Landscape Journal, however, never would have seen the light of day without the constant and direct assistance of one individual: Steve Miller, Journals Manager for the University of Wisconsin Press. It was he whom we first contacted when the idea of a journal became something more than just another item for discussion at CELA meetings. When the 1980 CELA conference was held in Madison, Wisconsin, Steve was ready to pledge his support and that of the UW Press to the proposal we had formulated. Since then, he has been an unflagging advocate for Landscape Journal, and is always thinking of new ways to promote the good name of the publication and the discipline which it represents.

Other individuals certainly need to be recognized for their many and varied contributions to the Journal. Signe Holtz developed the procedures for cataloging and organizing the manuscripts that began to appear in our mail boxes at an increasing rate. George F. Thompson took on the arduous task of establishing and editing the book review section in 1983; Catherine Howett then served as book review editor before Nöel Dorsey Vernon assumed the duties in 1988.
Gregory Conniff and John Wendt generously shared their artistic talents by providing several photographs for early issues of the Journal. Anne Whiston Spirn agreed to serve as guest editor for a special 1988 issue on design in landscape architecture that was supported by a grant from the National Endowment for the Arts. And finally, the Department of Landscape Architecture at the University of Wisconsin -Madison and the School of Environmental Design at the University of Georgia (not to forget several administrators in both institutions) have been most supportive during our tenure as co-editors.

One of us (Morrison) already surrendered his co-editor's reins to Robert Riley of the University of Illinois during 1988, while the other (Alanen) agreed to stay on through 1989 to assist with the transition. The latter will remain as a Corresponding Editor for Landscape Journal to provide liaison with the University of Wisconsin Press, but will no longer be associated with day-to-day operations.

Once again, we thank you for the many favorable comments which have been directed our way for the period of time (almost a decade) that we have been associated with Landscape Journal. We trust that your support will continue as Robert Riley assumes sole responsibility for the task we shared over these previous years.

\section{Arnold Alanen}

Darrel Morrison 